\title{
Torque Control Strategy for Battery Electric Bus
}

\author{
Hu Jianyao ${ }^{1}$, Wu Juan ${ }^{2}$, Peng Hemeng ${ }^{1}$, Huang Qingli ${ }^{1}$, Luo Dongxiang ${ }^{1}$, Fan Linyong ${ }^{1}$, He Zhiyuan $^{1}$ and Xu Huawei ${ }^{1}{ }^{1 *}$ \\ ${ }^{1}$ China CEPREI Laboratory, No. 110 Dongguanzhuang Road, 510610 Guangzhou, China \\ ${ }^{2}$ Sun Yat-sen University, No. 135 Xingang Xi Road, 510275 Guangzhou, China
}

\begin{abstract}
As battery electric vehicles are gaining more and more popularity in the Chinese market, the role of the energy management system in the drivetrain is escalating. In this paper, the driving control strategy of a battery electric bus is presented. Applying a fuzzy logic control (FLC) algorithm, the output torque of electric machine is controlled and vehicle driving dynamics and acceleration performance are improved. Simulation results are shown and the pros and cons of FLC approach is discussed. The method proposed in this paper could be used and more practical experiments should be done for improvement in the future.
\end{abstract}

\section{Introduction}

With the crises of insufficient fossil fuel energy resources and their subsequent environmental problems such as greenhouse gases and global warming, renewable energy is viewed as a significant alternative energy source around the world. Automotive industry's focus has been shifting towards an emphasis on environmentally clean, more efficient and safe products [1]. This shift in the focus has caused major automotive companies to set the environment and efficiency as two of their most important goals and are working towards achieving them. According to the U.S. Department of Energy (USDE), about $15 \%$ of the total fuel energy is consumed to run a car and its other accessories. Most of the energy are transformed into heat during combustion which consequently and directly contribute towards global warming [2]. Therefore, interest in new solutions for the replacement of conventional internal combustion engine (ICE) based propulsion system in vehicular applications has increased steadily.

With the development of the battery and motor technology, battery electric vehicles (BEV) have gained tremendous attention from the past decade due to providing environment friendly operation with the usage of renewable fuel [3]. Electric vehicles are the high-tech products that integrated machinery, electronics, energy, computers, automobiles and information technology, the ultimate goal is to achieve intelligent, digital and lightweight. Additionally, an electric vehicle can convert the vehicle's kinetic energy to electric energy and store it during the braking and coasting [4]. The knowledge gained in this specific area, namely optimal control of the drivetrain focusing on electric machine, is demonstrated in this paper. Electric machine and drive system is a key component of electric vehicles. To enable the electric car to have a good performance, electric machine should have a wide speed range, high speed, high starting torque, fast response characteristic, high efficiency and power density. The accelerating time is one of the key indexes to measure the vehicle dynamic performance. As a result, the merits of torque control strategy has a direct influence on the accelerating performance of the electric car.

Up to now, many papers have discussed the driving control strategy and most of the studies have employed the linear pedal driving control strategy. But few papers consider the insufficient torque of electric machine as the electric vehicle in speeding up and rush started conditions. Although some studies have considered the motor torque compensation as stepping on the accelerator pedal to the end, it is not obvious that this torque compensation can enhance the accelerating performance of battery electric vehicle [5-9].

By using the fuzzy logic algorithm, we can automatically control the output torque of electric machine and then further to improve the accelerating performance. A simple but effective approach is adopted throughout the article, and a battery electric city bus is considered as a case study.

This paper is organised as follows: in section 2 the simulation modelling is described and parameters of the battle electric city bus model developed for this research are given in detail. The fuzzy logic algorithm and the torque control strategy are formulated in section 3 . Simulation results and the conclusion of this work are presented in section 4 and section 5 respectively.

\section{Simulation Model Definition}

\subsection{Battery Electric Bus}

The test vehicle is a $14.35 \mathrm{t}$ battery electric city bus from Wuzhoulong Motors. The bus and parameters are summarized in Table 1.

Table 1. Parameters of The Bus.

\begin{tabular}{|c|c|c|}
\hline Description & Quantity & Unit \\
\hline Total mass (laden) & 18000 & $\mathrm{~kg}$ \\
\hline Frontal area & 6.5 & $\mathrm{~m}^{2}$ \\
\hline Drag coef. & 0.75 & - \\
\hline Rolling resistance coef. & 0.016 & - \\
\hline Air density & 1.202 & $\mathrm{~kg} / \mathrm{m}^{3}$ \\
\hline Wheel radius & 507 & $\mathrm{~mm}$ \\
\hline Length/width/height & $11490 / 2480 / 2910$ & $\mathrm{~mm}$ \\
\hline
\end{tabular}




\subsection{Battery}

The battery pack is the core of an electric vehicle. Recently lithium-ion batteries, which are essential for fully electrified vehicles due to their relatively high specific energy and power, a major step forward has been made in reducing costs and improving safety, performance and reliability. LiFePO4 battery has selected as an ideal power source for this electric bus. It's specifications can be seen in Table 2 .

Table 2. Specification of LiFePO4 Battery.

\begin{tabular}{|c|c|c|}
\hline Description & Quantity & Unit \\
\hline Nominal voltage & 3.2 & $\mathrm{~V}$ \\
\hline Nominal capacity & 5 & $\mathrm{Ah}$ \\
\hline Energy density & 130 & $\mathrm{Wh} / \mathrm{kg}$ \\
\hline Weight & 145 & $\mathrm{~g}$ \\
\hline Number of cells in parallel & 108 & - \\
\hline Number of cells in series & 168 & - \\
\hline
\end{tabular}

\subsection{Electric Machine}

Electric machines are a key component of an electric bus. The fact that an electric machine can be used to convert kinetic energy back into electrical energy is an important feature of electric vehicles [10]. The electric machine (YPQ220M-6) from Shanghai Technologies is applied. It is a brushless permanent magnet synchronous machine with the specifications in Table 3. The efficiency map of electric machine is shown in Fig. 1.

Table 3. Specifications of YPQ220M-6.

\begin{tabular}{|c|c|c|}
\hline Description & Quantity & Unit \\
\hline Nominal voltage & 3.2 & $\mathrm{~V}$ \\
\hline Nominal capacity & 5 & $\mathrm{Ah}$ \\
\hline Energy density & 130 & $\mathrm{Wh} / \mathrm{kg}$ \\
\hline Weight & 145 & $\mathrm{~g}$ \\
\hline Number of cells in parallel & 108 & - \\
\hline Number of cells in series & 168 & - \\
\hline
\end{tabular}

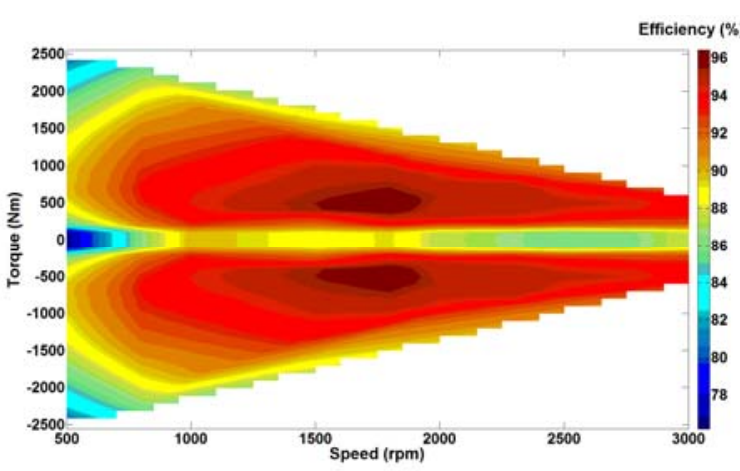

Figure 1. The Efficiency Map of Electric Machine.

\subsection{Simulation Model}

Figure. 2 shows the description of the simulation model of the battery electric bus in the AVL/Cruise software. Preceding the design of the torque control strategy, validity of the model must be established. The simulation model was validated using four primary tests: climbing performance, full load acceleration, the driving range and energy consumption. Relative errors were calculated and found to be less than $10 \%$ during all test.

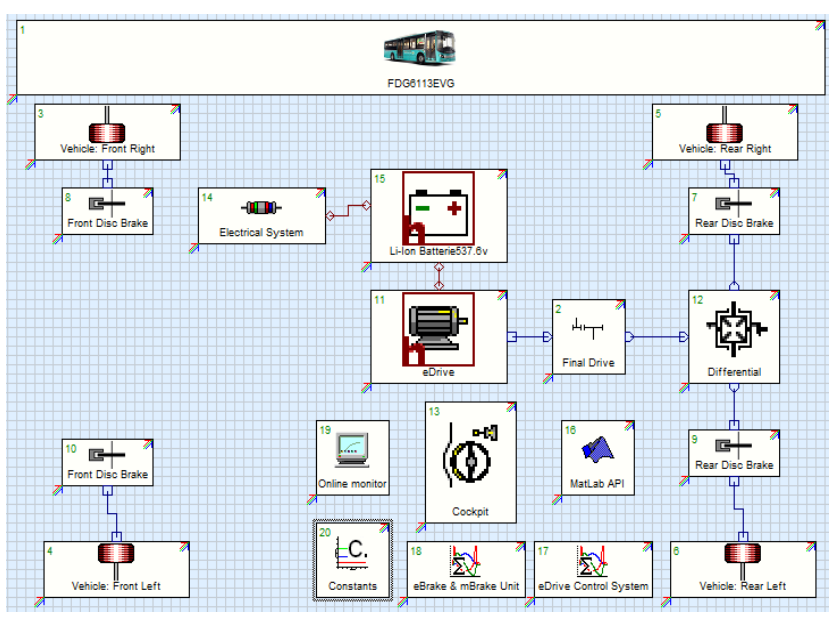

Figure 2. Simulation Model of the battery electric bus.

\section{Algorithm Description}

In the instant startup and rapidly speeding-up cases, traditional engines need more fuel injection to meet the driver's intentions. In the battery electric city bus, due to the presence of motor response time, the output torque of electric machine cannot fulfil the driver's torque demand in time. So, based on the fuzzy logic algorithm, we propose a driving control strategy to compensate the torque of electric machine.

\subsection{Fuzzy Logic Controller}

A fuzzy controller can be easily implemented provided the knowledge base and the membership functions are available [7]. As fuzzy logic permits systems to be controlled by heuristic representation of how the system behaves, we exploit this feature to generate the compensate torque reference output of 
electric machine. The scheme of the control strategy in more details is shown in Fig. 3. we adopt Mamdani's fuzzy inference method because it is intuitive, widespread acceptance and well suited to human input.

The input variables of the fuzzy controller are:

- Accelerator Pedal Opening (APO);

- Accelerator Pedal Opening Ratio $(\triangle \mathrm{APO})$.

The output variable of the fuzzy controller is:

- Additional Torque $(\Delta \mathrm{T})$.

When the accelerator pedal opening is large, battery electric bus can increase the power output to meet the demand of high-speed bus or heavy load force condition. When the accelerator pedal ratio increases, bus can speed up rapidly.

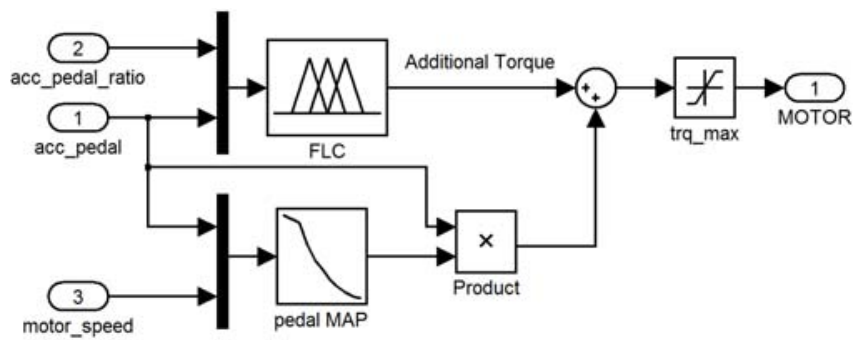

Figure 3. Block Diagram of The Control Strategy.

\subsection{Membership Functions}

It will keep the number of decision rules reasonably low and minimize the processing time if the number of sets of each membership function is reduced. The input and output membership functions are shown in Fig. 4, Fig. 5 and Fig. 6. The range of APO and $\triangle \mathrm{APO}$ are split ed into small (S), middle (M), big (B) and maximum (ZB). The range of $\Delta \mathrm{T}$ is splitted into minimum (ZS), small (S), middle (M), big (B) and maximum (ZB).

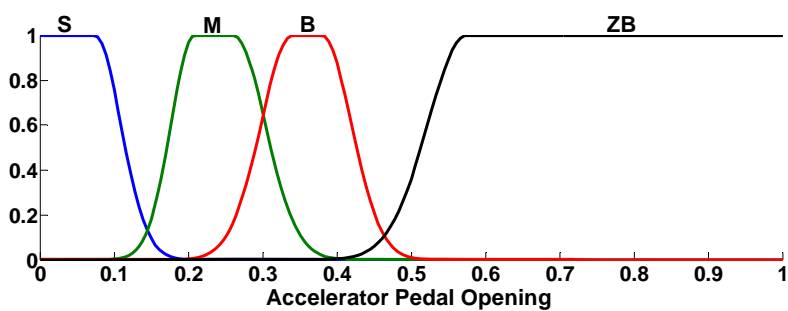

Figure 4. Input Membership Functions.

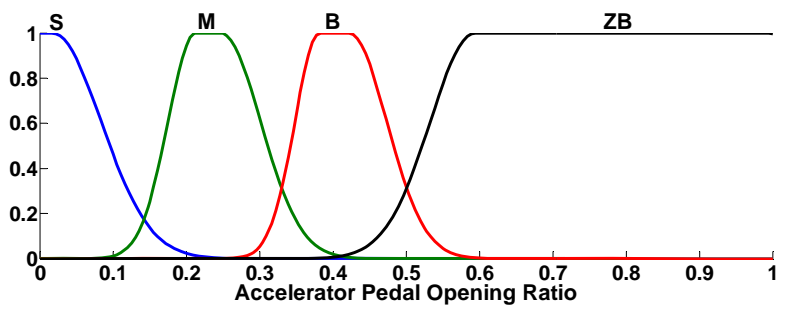

Figure 5. Input Membership Functions.

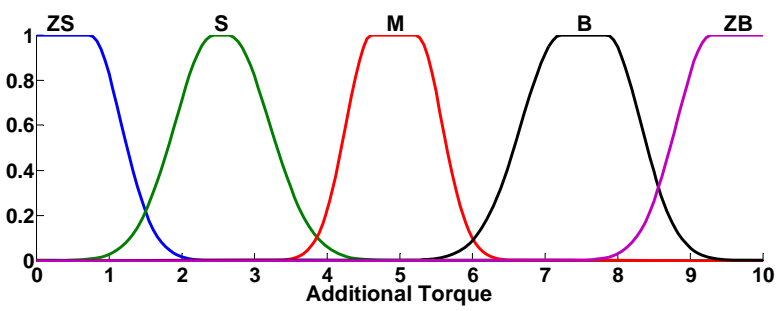

Figure 6. Output Membership Functions

\subsection{Fuzzy Rule-based System}

Rules form the basis for the fuzzy logic to obtain the fuzzy output. The fuzzy rule-based system uses IF-THEN rule-based system, given by, IF antecedent, THEN consequent. Fuzzy rules for the control system are written in the following form:

- if $\mathrm{APO}$ is $\mathrm{S}$ and $\triangle \mathrm{APO}$ is $\mathrm{S}$ then $\triangle \mathrm{T}$ is $\mathrm{ZS}$;

- if $\mathrm{APO}$ is $\mathrm{S}$ and $\triangle \mathrm{APO}$ is $\mathrm{M}$ then $\triangle \mathrm{T}$ is $\mathrm{M}$;

- if $\mathrm{APO}$ is $\mathrm{S}$ and $\triangle \mathrm{APO}$ is $\mathrm{B}$ then $\triangle \mathrm{T}$ is $\mathrm{B}$;

- if APO is $\mathrm{S}$ and $\triangle \mathrm{APO}$ is $\mathrm{ZB}$ then $\triangle \mathrm{T}$ is $\mathrm{ZB}$;

- if APO is M and $\triangle \mathrm{APO}$ is $\mathrm{S}$ then $\triangle \mathrm{T}$ is $\mathrm{ZS}$;

- if $\mathrm{APO}$ is $\mathrm{M}$ and $\triangle \mathrm{APO}$ is $\mathrm{M}$ then $\triangle \mathrm{T}$ is $\mathrm{S}$;

- if APO is M and $\triangle \mathrm{APO}$ is $\mathrm{B}$ then $\triangle \mathrm{T}$ is $\mathrm{M}$;

- if $\mathrm{APO}$ is $\mathrm{M}$ and $\triangle \mathrm{APO}$ is $\mathrm{ZB}$ then $\triangle \mathrm{T}$ is $\mathrm{B}$;

- if APO is B and $\triangle \mathrm{APO}$ is $\mathrm{S}$ then $\triangle \mathrm{T}$ is $\mathrm{ZS}$;

- if $\mathrm{APO}$ is $\mathrm{B}$ and $\triangle \mathrm{APO}$ is $\mathrm{M}$ then $\triangle \mathrm{T}$ is $\mathrm{S}$;

- if $\mathrm{APO}$ is $\mathrm{B}$ and $\triangle \mathrm{APO}$ is $\mathrm{B}$ then $\triangle \mathrm{T}$ is $\mathrm{S}$;

- if APO is B and $\triangle \mathrm{APO}$ is $\mathrm{ZB}$ then $\triangle \mathrm{T}$ is $\mathrm{M}$;

- if $\mathrm{APO}$ is $\mathrm{ZB}$ and $\triangle \mathrm{APO}$ is $\mathrm{S}$ then $\triangle \mathrm{T}$ is $\mathrm{ZS}$;

- if APO is ZB and $\triangle \mathrm{APO}$ is $\mathrm{M}$ then $\triangle \mathrm{T}$ is $\mathrm{ZS}$;

- if $\mathrm{APO}$ is $\mathrm{ZB}$ and $\triangle \mathrm{APO}$ is $\mathrm{B}$ then $\triangle \mathrm{T}$ is $\mathrm{S}$;

- if $\mathrm{APO}$ is $\mathrm{ZB}$ and $\triangle \mathrm{APO}$ is $\mathrm{ZB}$ then $\Delta \mathrm{T}$ is $\mathrm{S}$.

After the formulation of fuzzy control rules, we can obtain the characteristic graph (Fig. 7) of the fuzzy logic controller.

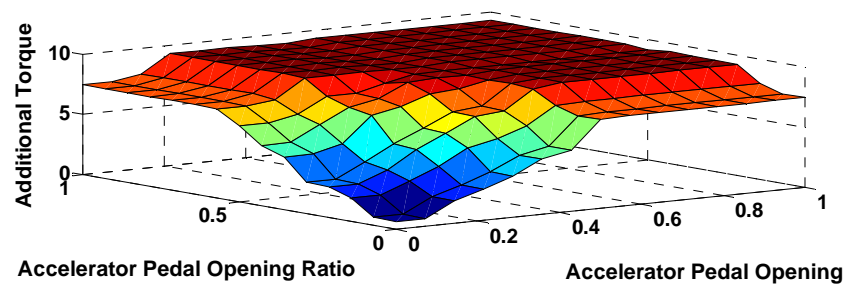

Figure 7. The Characteristic Graph of Fuzzy Logic.

\section{Simulation Results}

The torque control results are plotted in Fig. 8. It shows that, considering the change of the accelerator pedal opening and the different motor speed $(600 \mathrm{rpm}$, $1200 \mathrm{rpm}$ and $2000 \mathrm{rpm}$ ), the torque control strategy plays a effective role to compensate torque to a different extent. Fig. 9 shows the accelerating time of battery electric bus with torque control strategy. This two figures show that, the control strategy would compensate the torque of electric machine so as to reduce the accelerating time of battery electric bus. From 0 to $50 \mathrm{~km} / \mathrm{h}$ accelerating condition, the proposed control strategy enables to reduce the accelerating time by $3.5 \%$. 


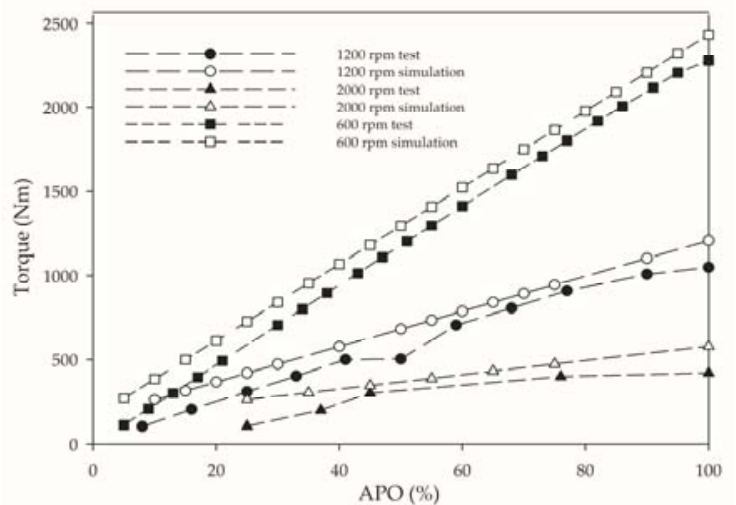

Figure 8. Torque Control Results.

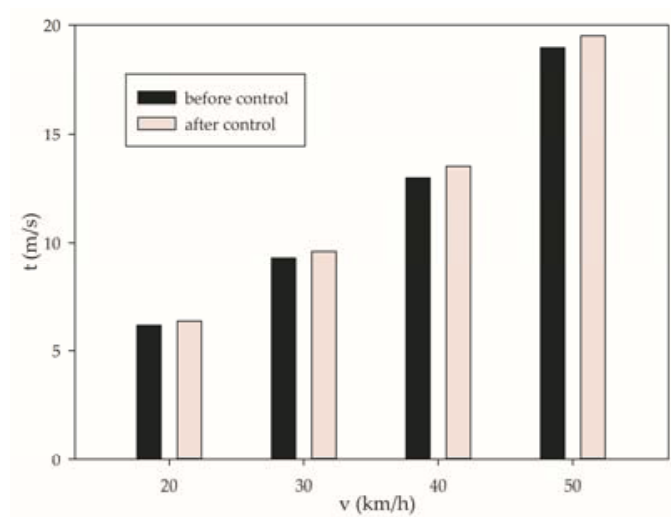

Figure 9. The Accelerating Time.

\section{Conclusions}

This paper presents the torque control strategy for the battery electric city bus application based on the fuzzy logic controller. The simulation model and parameters of the battery electric city bus is presented. The torque control method is proposed. Comparisons are shown between the battery electric city bus simulation model integrated with the torque control strategy, and model that without any control strategy. The results enable to conclude that, the proposed method for electric bus driving conditions is effective and the dynamic performance of the battery electric bus is enhanced.

Future work could benefit from optimizing the parameters of the fuzzy logic controller and developing the highest efficiency but lowest energy consumption law of electric machine. The efficiency of powertrain system could be considered according to the different driving conditions. More importantly, experimental verification should be done in the future.

\section{References}

[1] C.C. Chan, et al., Modern Electric Vehicle Technology, ISBN 0-19-850416-0, New York, Oxford University Press, 2001.

[2] K.T. Chan, et al., Emerging Energy-efficient Technologies for Hybrid Electric Vehicles, Proceedings of the IEEE, ISSN 0018 9219, 95(2007), 821-835
[3] I. Husain, Electric and hybrid Vehicles: design fundamentals, ISBN 978-7-111-37351-3, London, CRC Press, 2011.

[4] James Larminie, John Lowry. "Electric Vehicle Technology Explained." New York: John Wiley \& Sons, Ltd. 2003.

[5] Wang Liguo. "Study on Powertrain Control Strategy for an Electric Bus." PhD diss., Jilin University, 2009.

[6] Dou Guowei, Liu Feng, Cheng Hao, Ke Xiaojun and Kou Gonghong. "Development Practice of Vehicle Driving Control Strategy of Electric Vehicle." Shanghai Automobile 31 (2009): 362-365.

[7] Wang Jia, Yang Jiangzhong, Cai Zhibiao and Zhang Xiang. "The Optimal Control Strategy of Battery Electric Car Based on Fuzzy Control." Automotive engineering 5 (2010): 8-12.

[8] Zhou Mengxi. "Study on Control Strategy for Electric Vehicle at Drive Condition." Master diss., Chongqing University, 2012.

[9] Austin Hughes. "Electric Motors and Drives: Fundamentals, Types and Applications." Oxford: Elsevier Ltd. 2006.

[10] S. N. Sivanandam, S. Sumathi and S. N. Deepa. "Introduction to Fuzzy Logic using MATLAB." Springer. 2007. 